\section{A Method to Quantitatively Classify Residential Urban Landscapes in a Desert Environment}

\author{
Malik G. Al-Ajlouni ${ }^{1}$, Dawn M. VanLeeuwen ${ }^{2}$, \\ Michael N. DeMers ${ }^{3}$, and Rolston St. Hilaire ${ }^{1,4}$
}

AdDitional INDEX wORDs. landscape layers, landscape type, turf, urban land cover

SUMMARY. The apparent heterogeneity of human-generated materials in residential urban landscapes sustains concerns that the quantitative classification of urban residential landscapes is impossible. The objective of this research was to develop a method to quantitatively classify urban residential landscapes in a desert environment. Using a purposive sampling procedure, we studied the landscapable area around each of 54 residential homes in Las Cruces, NM. All materials in the landscape were identified, measured, and categorized. Using $30 \%$ as the cutoff to indicate that a material was dominant in the landscape, we classified $93 \%$ of all landscapes into nine common landscape types. Mulch-dominant landscapes were the most common, and landscape types differed between front- and backyards. Shrubs did not feature prominently in any of the common landscape types. Our classification method clearly identifies multiple landscape types, and for the first time, provides quantitative evidence that landscape types are distributed differently in front- and backyard landscapes in the desert environment of Las Cruces. Information on common landscape types will be valuable to landscape horticulturists wanting to craft water conservation plans that are landscape specific if the common landscape type can be linked to a landscape water budget.

$\mathrm{U}$ rban residential landscapes are dynamic, varied, and complex, which makes their classification challenging (Grimm et al., 2000). Furthermore, the plant community, which is the basic unit that landscape ecologists use to classify natural landscapes, is not relevant to residential landscapes. A plant community is a group of plants whose constitution and relation to identifiable environmental conditions give them observable group identities (Hunter and Paysen, 1986). While several reports detail how large-scale (e.g., citywide) urban land cover is classified (Myeong et al., 2001; Richards et al., 1984), it is unfortunate that mainly descriptive parameters such as plant material type (Larsen and Harlan, 2006) and plant water-use characteristics (Yabiku et al., 2008) are used to classify the landscape around residences.

We thank the National Oceanic and Atmospheric Administration for financial support of this work through Grant Number GR0002372 to New Mexico State University.

${ }^{1}$ Department of Plant and Environmental Sciences, New Mexico State University, Box 30003, Las Cruces, NM 88003

${ }^{2}$ Agricultural Biometric Service, New Mexico State University, Las Cruces, NM 88003

${ }^{3}$ Department of Geography, New Mexico State University, MSC 3335, Box 30001, Las Cruces, NM 88003

${ }^{4}$ Corresponding author. E-mail: rsthilai@nmsu.edu.
Larsen and Harlan (2006) toured eight Phoenix, AZ, residential neighborhoods and categorized landscapes in those neighborhoods into desert, lawn, oasis, and courtyard landscape types. They described landscape types but did not quantitatively classify the landscape type. For example, the desert landscape type was described as "a landscape that featured plants that appear consistent with the Sonoran Desert's native plant palette." Based on the type of vegetation and the presence or absence of an irrigation system, Martin (2003) and Yabiku et al. (2008) described residential landscapes in North Desert Village, Phoenix, $\mathrm{AZ}$, as native desert, xeric, oasis, and mesic. The mesic landscape had no native desert plants, was sprinkler or flood irrigated, and had extensive turfgrass. In contrast, a xeric landscape had some native desert plants, minimal drip irrigation, and no turf (Yabiku et al., 2008).

There are solid scientific reasons to quantitatively classify urban residential landscapes. Godefroid and Koedam (2007) cautioned that many studies have failed to show a relationship between urban landscape type and plant species composition because the subunits of the landscape were not categorized quantitatively. Kenney et al. (2004) and more recently, Al-Kofahi et al. (2012a) showed that quantitative assessments of residential urban landscapes facilitate urban water conservation because accurate landscape water budgets can be calculated for those landscapes. Al-Kofahi et al. (2012b) established that accounting for the area and type of all individual materials within the landscape provided more accurate estimates of landscape water use than methods that neglected to do so.

Recognizing that urban residential landscapes change with time, are multidimensional, and heterogeneous because of human-generated plant groupings, we hypothesized that within a geographically defined area, a quantitative and repeatable method can be developed to classify urban residential landscapes. The objective of this research was to develop a quantitative and repeatable method to classify urban residential landscapes in a desert environment.

\section{Materials and methods}

SAMPLING. We designed a purposive sampling procedure to study 54 urban residential landscapes. To secure the needed sample size, we first selected randomly nine urban residential properties in each of three vegetation density categories in each of the six council districts (a total of 162 homes) of Las Cruces, NM (Fig. 1) from aerial and satellite images of Virtual Earth 3D 4.0 (Microsoft, Redmond, WA), Google Earth 4.3 (Google, Mountain View, CA), and online maps of Las Cruces (City of Las Cruces, 2008). Council districts had similar population sizes and thus represented a statistically balanced sampling stratum. A vegetation density category around each property was selected to capture the range of landscapes and was estimated

\begin{tabular}{llll}
\hline $\begin{array}{l}\text { Units } \\
\begin{array}{l}\text { To convert U.S. to SI, } \\
\text { multiply by }\end{array}\end{array}$ & U.S. unit & SI unit & $\begin{array}{l}\text { To convert SI to U.S., } \\
\text { multiply by }\end{array}$ \\
\hline 0.3048 & $\mathrm{ft}$ & $\mathrm{m}$ & 3.2808 \\
25.4 & inch(es) & $\mathrm{mm}$ & 0.0394 \\
1.6093 & mile $(\mathrm{s})$ & $\mathrm{km}$ & 0.6214
\end{tabular}




\section{City of Las Cruces Council Districts}

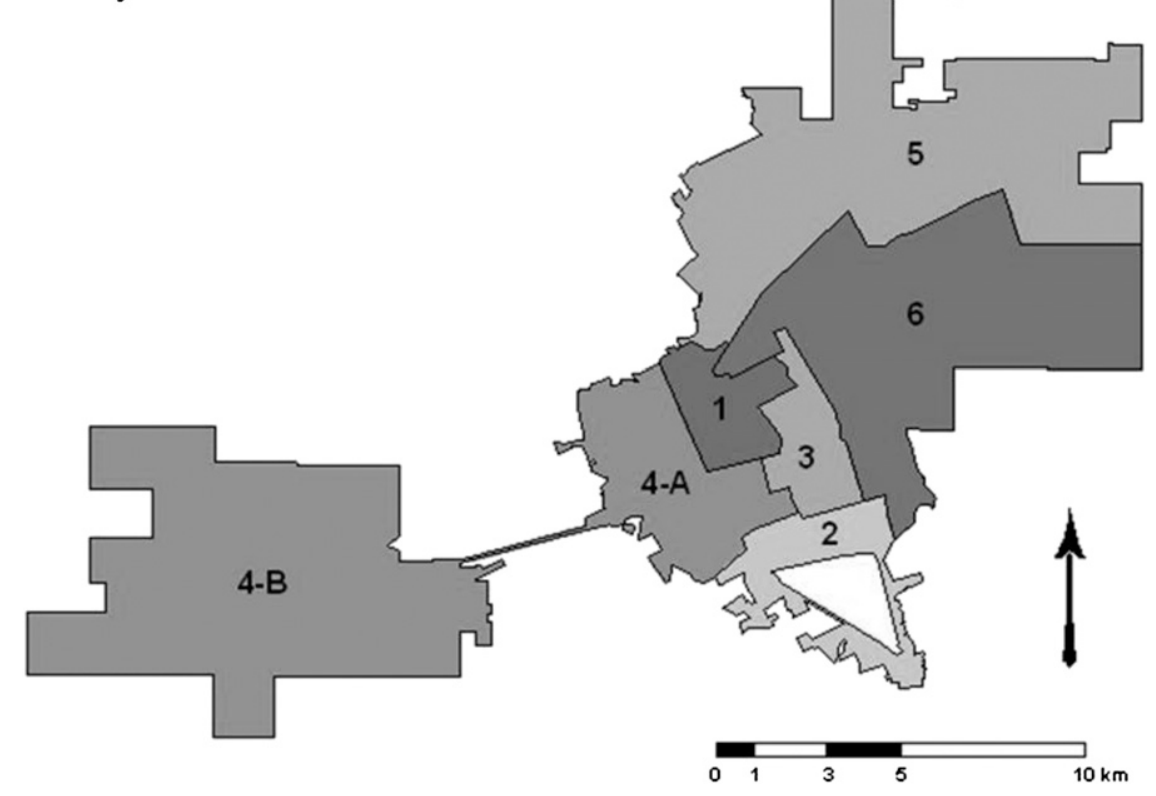

Fig. 1. Landscapes around nine residential homes in urban areas in each of the six (areas 1 to 6) City of Las Cruces, NM, Council Districts were sampled and used to classify urban residential landscapes. District 4-B is the Las Cruces International Airport, so it was not sampled. Council District sizes were based on population values of the 2000 U.S. population census; $1 \mathrm{~km}=0.6214$ mile.

visually on a scale of $0 \%$ to $100 \%$, where low $=$ less than $35 \%$, medium $=$ $36 \%$ to $65 \%$, and high $=66 \%$ and higher. On 18 May 2009, we mailed an envelope of materials to each owner of the 162 homes. The envelope included a letter that explained our project and incentives for participating, a permission slip requesting a signed consent to visit their landscape, and a preaddressed stamped envelope for returning the consent form. To encourage participation, the letter explained that participants would be entered in a raffle for a chance to win one of eight $\$ 50$ gift cards from Walmart (Bentonville, AR). Reminder cards were sent to nonresponders on 9 and 24 June 2009. On 21 Aug. 2009, we closed the window of time for receiving permission from homeowners. Although the response rate (27.7\%) was relatively low, only an additional nine were needed to meet our target sample size of 54 . We secured these nine landscapes by driving through the neighborhoods in districts $1,2,4$, and 6 where respectively, 1, 4, 1, and 3 additional samples were needed and solicited permission from the homeowners.

Data collection. Data collection started on 25 Aug. 2009 and ended on 18 Dec. 2009. We used a parcel map from the City of Las Cruces' online maps (City of Las Cruces, 2008) to We visited each of the 54 residential sites, measured dimensions (e.g., canopy size of trees, length and width of pavement) and relative distances of all landscape items with a laser distance meter (DISTO D8; Leica, St. Gallen, Switzerland). We created (handsketched) the actual landscape design, exclusive of rights-of-way, for each landscape and classified plant materials as tree, shrub, herbaceous, vine, and warm or cool season turf. Other landscape materials were classified as mulch (gravel, shredded wood, and sand), hard surface (concrete, asphalt, and flagstone), shade structure (house extension, arbor, and gazebo), and water feature (swimming pool, fountain, and pond). Plants and water features that required water to function were designated as irrigated materials. Plants were categorized into water-use levels based on data mined from the published literature (Costello and Jones, 1999). All plant species, color and sieve size of inorganic mulch, dimensions of all hardscapes, and the sizes of all water features were located on the hand drawing. As a verify each property's legal boundary. backup, and to assist with plan drawing and plant identification, multiple photographs of all landscapes were taken. We used AutoCAD 2010 (Autodesk, San Rafael, CA) to prepare final plans from the hand drawings.

The landscape of each of the 54 residential properties was divided into zones (Fig. 2) to account for differences between front- and backyard landscapes. Las Cruces residents have self-reported a willingness to use different plants in their front- and backyards (Spinti et al., 2004). Sideyards were either part of the front- or backyard landscape zone (Fig. 2).

There were 158 landscape zones or about three zones for each of the 54 landscapes. The AutoCAD drawing was used to determine the area of every landscape material within the landscapable area of each zone. Landscapable area of each zone was defined as all land area (ground layer) exclusive of the driveway, entrance, and storage areas. We noted whether the landscape materials formed part of the ground, vertical, or ceiling layer of the landscape. For materials in the vertical (e.g., vines at side the of an arbor) and ceiling layer (e.g., trees and shrubs), we noted whether there was overlap (e.g., tree over a shrub). Consequently, landscape material percentage could exceed $100 \%$ of the landscapable area. Thus, our data collection method accounted for landscape layers which are often ignored in urban land cover classification methods that use plan views, photographs, or satellite images.

LANDSCAPE ClASSIFICATION. We used coverage (percent cover of the landscape material in the landscapable area) of each landscape material in a zone for classification. We named the landscape type based on the modified method of Hunter and Paysen (1986) that used coverage(s) of dominant materials to name a landscape. We judged the woodland natural landscape, which had a tree canopy cover from 25\% to 60\% (Hunter and Paysen, 1986), as the natural landscape that most closely resembled the isolated trees of urban landscapes in desert environments. For that reason, we evaluated coverage percentages near $25 \%(20 \%$ to $35 \%)$ to determine minimum percentage of landscape material needed to classify landscape zones (Table 1). For each of the 158 landscape zones, we calculated frequency as the number of times that a landscape 


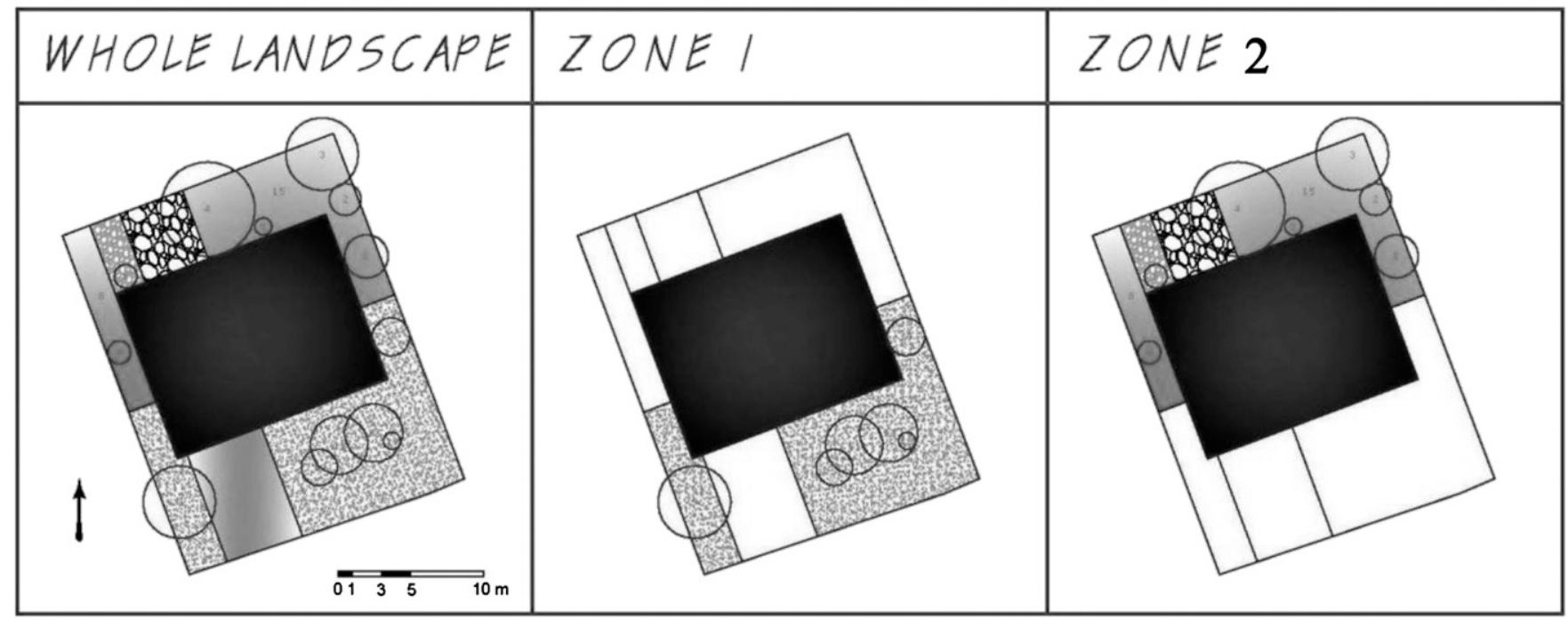

Fig. 2. A diagram showing how the entire landscapable area around a home in Las Cruces, NM, was divided into zones (two) that were used to classify residential landscapes. The solid dark rectangle represents the outline of the home. Areas around the solid dark rectangle, exclusive of the driveway (shaded rectangle on the bottom of the left figure) represent the landscapable areas. Circles represent trees or shrubs; $1 \mathrm{~m}=3.2808 \mathrm{ft}$.

material was present in a landscape zone.

A modified Thiessen polygon method (Klein, 1989) was used to calculate the areas of overlapping plants in vertical and ceiling layers when there was overlap. With this method, half the distance between the centers of plants was used to separate the areas of individual plants that overlapped. In this way, overlapping canopy area was not counted twice.

Statistical analysis. We used SAS statistical software (version 9.2; SAS Institute, Cary, NC) for all statistical analyses. Significance was defined for $P<0.05$. The sizes of landscape zones varied. For that reason, landscape materials coverage data from all landscape zones were standardized to a per unit area basis before classification. A mixed model was used to compare the mean number of different plant species and mean total number of plants among common landscape types. We excluded minor landscape types in the analysis due to insufficient replication. Hard-surface shade-structure landscape types were removed from the analysis due to uniform zeros (there were no plants). When differences among landscape types were detected, the Tukey-Kramer mean separation test was used.

We used a modified outlier strategy (Ramsey and Schafer, 2002) to assess sensitivity of the analysis to skew. Observations with studentized
Table 1. Assessment of the minimum percentage of landscape material coverage in the landscapable area (zones) of a residence that was needed to categorize residential landscapes in Las Cruces, NM, into a common landscape type. When three or more landscape zones had the similar minimum percentage of landscape coverage material, they were categorized into a common landscape type.

\begin{tabular}{lcc}
\hline $\begin{array}{l}\text { Minimum portion } \\
\text { of landscape material (\%) }\end{array}$ & $\begin{array}{c}\text { Common landscape } \\
\text { types (no.) }\end{array}$ & $\begin{array}{c}\text { Landscape zones in Las } \\
\text { Cruces classified into } \\
\text { common landscape types (\%) }\end{array}$ \\
\hline 20 & 13 & 88 \\
25 & 10 & 91 \\
30 & 9 & 93 \\
35 & 9 & 92 \\
\hline
\end{tabular}

${ }^{\mathrm{z}}$ One hundred fifty-eight zones were analyzed.

y One hundred forty-seven zones were classified into common landscape types and 11 were classified as minor landscape types.

Table 2. Mean number of different plant species and mean total number of plants per common landscape type present in Las Cruces, NM. When three or more landscape zones had the similar minimum percentage of landscape coverage material, they were categorized into a common landscape type. Frequency $(N=147)$ of occurrence of each landscape type in Las Cruces, NM, is given.

\begin{tabular}{lccc}
\hline Common landscape type & $\begin{array}{c}\text { Frequency } \\
(\%)\end{array}$ & $\begin{array}{c}\text { Different } \\
\text { plant species (no.) }\end{array}$ & $\begin{array}{c}\text { Total } \\
\text { plants (no.) }\end{array}$ \\
\hline Hard-surface shade-structure & 8 & 0 & 0 \\
Mulch & 39 & $6 \mathrm{a}^{\mathrm{z}}$ & $15 \mathrm{a}$ \\
Hard-surface & 5 & $3 \mathrm{a}$ & $6 \mathrm{a}$ \\
Hard-surface mulch & 3 & $4 \mathrm{a}$ & $12 \mathrm{a}$ \\
Mulch tree & 12 & $6 \mathrm{a}$ & $14 \mathrm{a}$ \\
Turf mulch & 6 & $7 \mathrm{a}$ & $13 \mathrm{a}$ \\
Turf & 6 & $7 \mathrm{a}$ & $13 \mathrm{a}$ \\
Tree mulch turf & 5 & $10 \mathrm{a}(12)^{\mathrm{y}}$ & $26 \mathrm{a}(38)$ \\
Turf tree & 9 & $8 \mathrm{a}$ & $16 \mathrm{a}$ \\
\hline
\end{tabular}

${ }^{2}$ Numbers within the column followed by the same letters are not significant different based on least square means separation of Tukey-Kramer test $(P \leq 0.05)$. Least square means separation was carried out after removing outliers. ${ }^{y}$ Data in parentheses are the value before removing the outliers. 

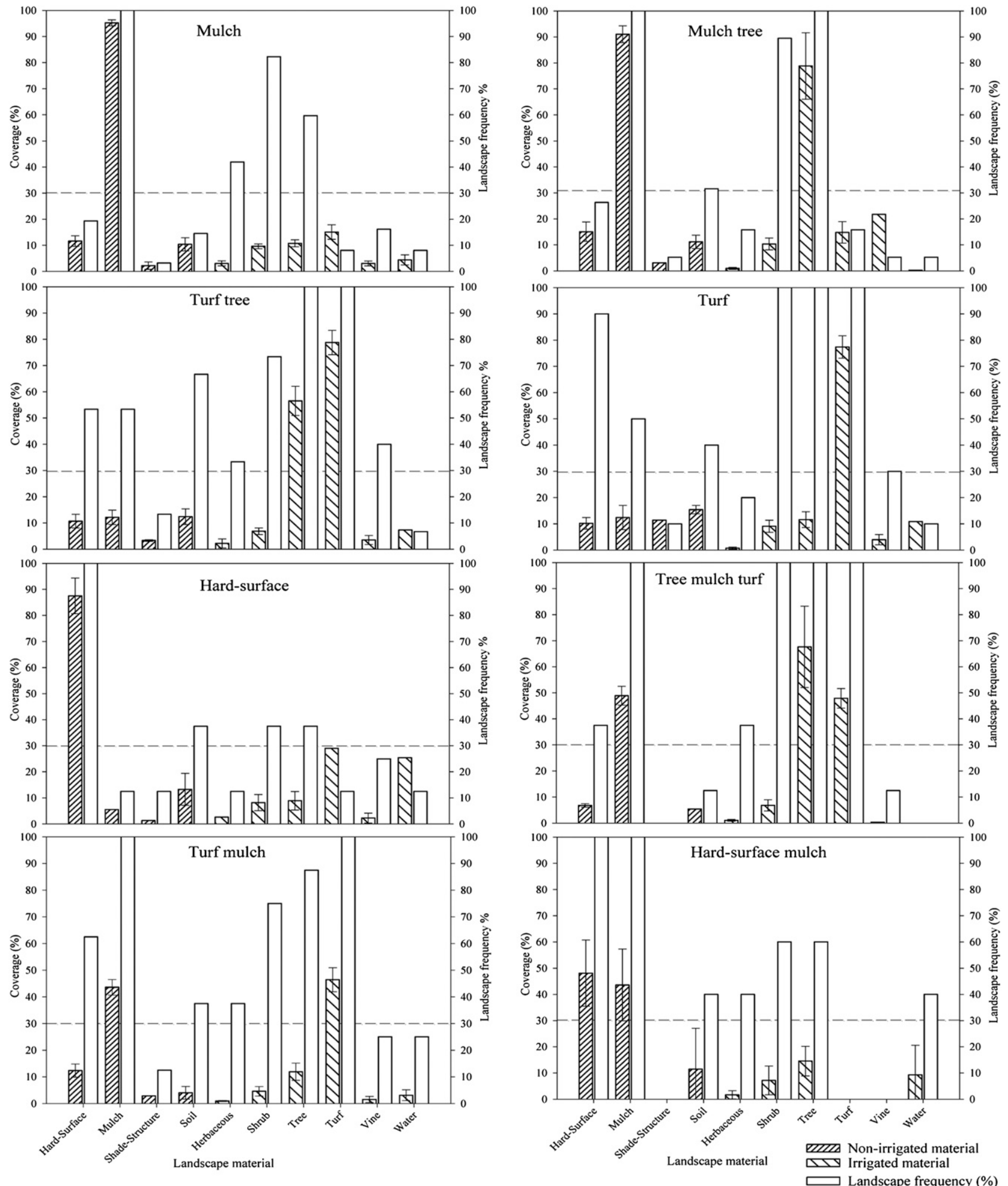

Fig. 3. Coverage and frequency percentage of the landscape materials in common landscape types of Las Cruces, NM. The name of a common landscape type [mulch, mulch tree, turf tree, turf, hard-surface, tree mulch turf, turf mulch, hard-surface, hardsurface shade-structure (not shown)] consisted of the name(s) of the landscape material that covered at least $30 \%$ of the landscapable area. Names are ordered in decreasing order of landscape material coverage percentage. Coverage percentage is the average percent of landscape zones containing that landscape material. Landscape frequency percentage is the average percent of landscape zones containing the material. Error bars represent standard error of the mean. The dashed horizontal line shows the minimum percentage $(30 \%)$ of coverage material required for that material to appear in the name of the landscape type. 
residuals that were greater than three were removed before conducting mean separation. One outlier each was removed for the mean number of different plant species and the mean total number of plants in a common landscape type.

Using presence-absence indicators, the McNemar's statistical test applied to each pair of indicators was used to determine the most common trees, shrubs, herbaceous, and vines that were present in landscapes (Sun and Yang, 2008). In addition, the $\mathrm{McNemar}$ 's test was used to examine the differences in distribution of common landscape types within frontand backyards.

\section{Results}

We defined a common landscape type as a group of three or more landscapes that had similar minimum coverage percentages of a dominant landscape material. Analysis of 20\%, $25 \%, 30 \%$, or $35 \%$ coverage of a landscape material of the landscape zone revealed that $30 \%$ coverage had among the fewest number of common landscape types while classifying among the highest number of landscapes (Table 1). For that reason, we selected $30 \%$ landscape material coverage as the cutoff to designate that a landscape material was dominant.

A landscape name consisted of the names of the dominant material in decreasing order of dominance (Table 2; Fig. 3). A landscape material had to form at least $30 \%$ of the landscape area to appear in the name. For example, a turf tree (Fig. 3) landscape type had at least 30\% turf cover and $30 \%$ tree cover, but turf had a larger share of the coverage of the landscapable area. Landscape types with fewer than three representatives were considered as minor landscape types and formed the remaining $7 \%$ of landscapes. Mulch landscape type formed the majority of common landscape types (Table 2; Fig. 3).

Mulch had the largest coverage and frequency (Fig. 4) and was distributed as $98 \%$ gravel, $1 \%$ sand, and $1 \%$ shredded wood. Regardless of color, gravel in the medium textural class ( $\geq 10$ and $\leq 40 \mathrm{~mm}$ ) had the largest coverage value (Fig. 5). Very low, low, low-to-moderate, and moderate wateruse plants covered over half of the landscape types (55\%). Afghan pine (Pinus eldarica), oleander (Nerium oleander), red yucca (Hesperaloe parviflora), and honeysuckle (Lonicera japonica) were the most common tree, shrub, herbaceous plant, and vine, respectively. Warm season grass was the most common turfgrass (Table 3 ). Mulch landscape was the most widespread common landscape type in the frontyard (Table 4). Mulch also was

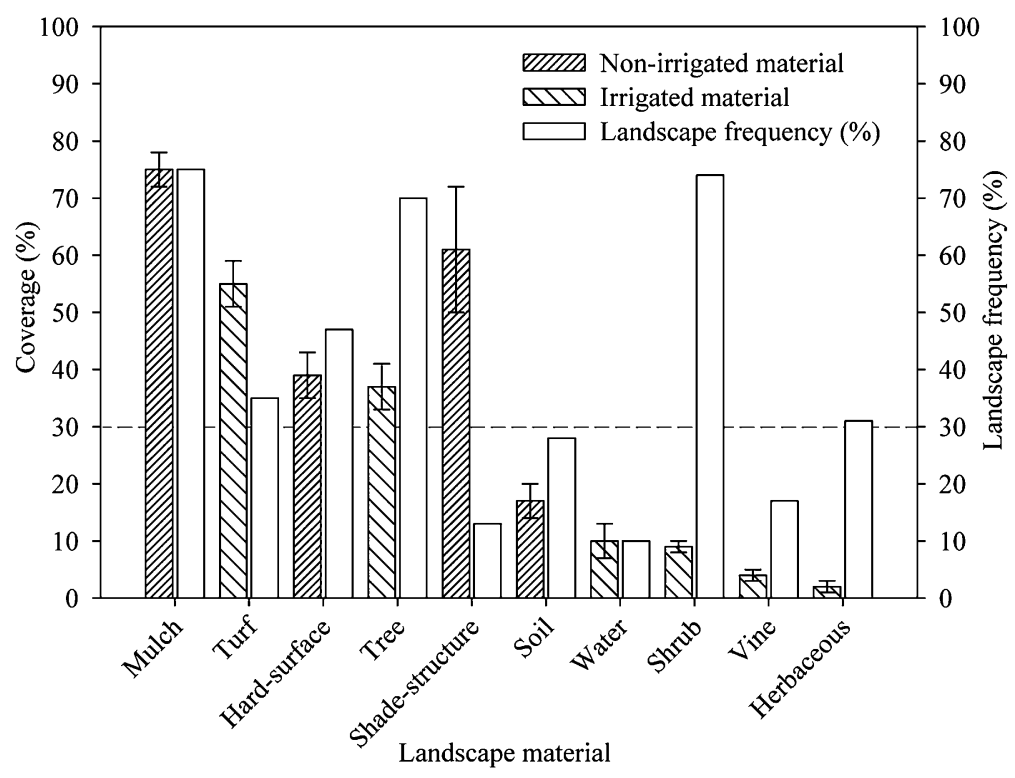

Fig. 4. Overall coverage and frequency of the landscape materials in landscapes of Las Cruces, NM. Coverage percentage is the overall coverage of the landscape material in a landscape zones. Landscape frequency is the number of landscape zones containing the material. Irrigated materials require water to function and nonirrigated materials do not. Error bars represent standard error of the mean $(N=$ 158). The dashed horizontal line shows the minimum percentage (30\%) of coverage material required for that material to appear in the name of the landscape type.

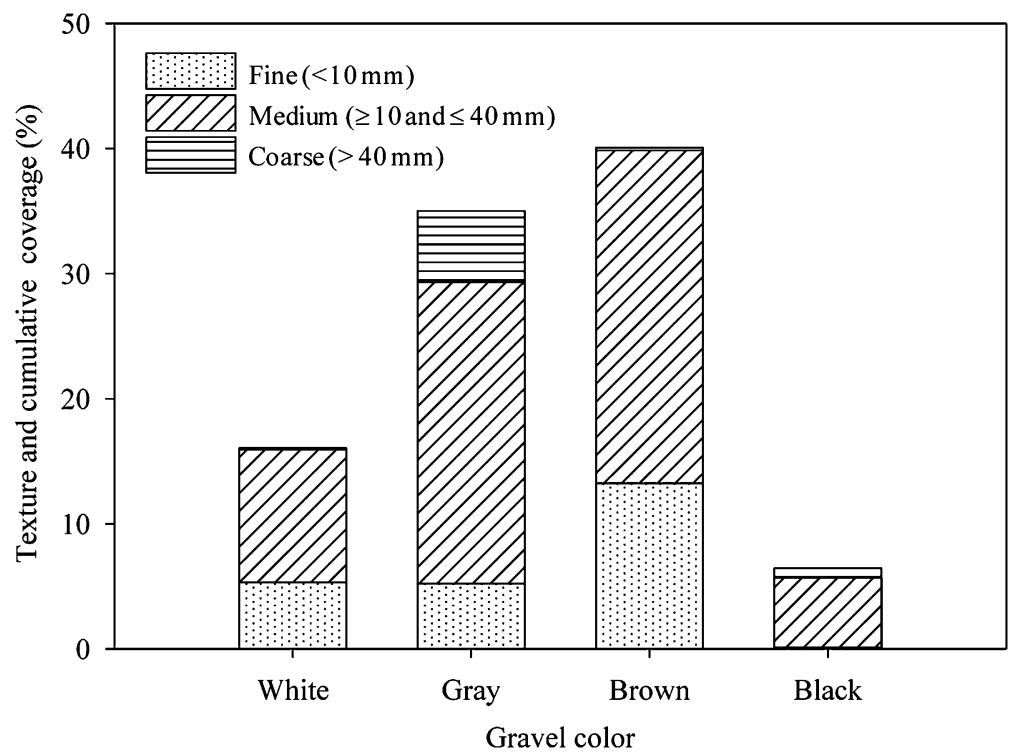

Fig. 5. Color and textural class distribution and cumulative coverage of gravel present in landscapes around urban residential homes sampled in Las Cruces, NM; 1 $\mathrm{mm}=0.0394$ inch . 
Table 3. Distribution of irrigated materials, their water-use level, the number of species, and coverage distribution in landscapes of Las Cruces, NM.

\begin{tabular}{|c|c|c|c|c|c|c|}
\hline \multirow{2}{*}{$\begin{array}{l}\text { Irrigated } \\
\text { material }\end{array}$} & \multirow[b]{2}{*}{ Water-use level } & \multicolumn{4}{|c|}{ Species $(\text { no. })^{\mathrm{z}}$} & \multirow{2}{*}{$\begin{array}{c}\text { Coverage } \\
(\%)\end{array}$} \\
\hline & & $\overline{\text { Tree }}$ & Shrub & Herbaceous & Vine & \\
\hline \multirow[t]{7}{*}{ Plants } & Very low & 0 & 1 & 0 & 0 & 0 \\
\hline & Very low to low & 0 & 4 & 1 & 0 & 1 \\
\hline & Low & 10 & 9 & 6 & 0 & 19 \\
\hline & Low to moderate & 17 & 26 & 7 & 5 & 17 \\
\hline & Moderate & 15 & 23 & 14 & 6 & 18 \\
\hline & Moderate to high & 4 & 0 & 2 & 0 & 5 \\
\hline & High & 2 & 0 & 0 & 0 & 0 \\
\hline \multirow[t]{3}{*}{ Turfgrass } & Moderate (warm season) & & & & & 34 \\
\hline & Moderate-high (mixed) & & & & & 2 \\
\hline & High (cool season) & & & & & 1 \\
\hline Water feat & & & & & & 2 \\
\hline
\end{tabular}

${ }^{2}$ Most frequently occurring tree was afghan pine; most frequently occurring shrub was oleander; most frequently occurring herbaceous plant was red yucca; most frequently occurring vine was japanese honeysuckle.

Table 4. Distribution of common landscape types between front- and backyards of residential landscapes $(N=147)$ in Las Cruces, NM. When three or more landscape zones had the similar minimum percentage of landscape coverage material, they were categorized into a common landscape type.

\begin{tabular}{lcr}
\hline & \multicolumn{2}{c}{ Distribution (\%) } \\
\cline { 2 - 3 } Common landscape type & Frontyard & Backyard \\
\hline Hard-surface shade-structure & 56.0 & $16.4 \mathrm{a}$ \\
Mulch & $2.7 \mathrm{c}$ & $27.4 \mathrm{a}$ \\
Hard-surface & $2.7 \mathrm{c}$ & $8.2 \mathrm{~b}$ \\
Hard-surface mulch & $2.7 \mathrm{c}$ & $4.1 \mathrm{~b}$ \\
Turf mulch & $18.9 \mathrm{~b}$ & $8.2 \mathrm{~b}$ \\
Mulch tree & $5.4 \mathrm{c}$ & $6.9 \mathrm{~b}$ \\
Turf & $5.4 \mathrm{c}$ & $8.2 \mathrm{~b}$ \\
Tree mulch turf & $5.4 \mathrm{c}$ & $5.5 \mathrm{~b}$ \\
Turf tree & & $15.1 \mathrm{a}$ \\
\hline
\end{tabular}

${ }^{\mathrm{z}}$ Numbers that share same letters within the column are not significantly different based on McNemar's test.

\section{Discussion}

This is the first report that details a formal procedure for quantitatively classifying residential urban landscapes in desert environments. And that method has allowed us to identify nine common landscape types (Table 2). While the percentage that is used to designate the cutoff for classification might differ, urban landscape horticulturists in other regions can use this method to find the common urban landscape types that exist in their area. Appearance of a landscape material in the landscape name implied that the material formed at least $30 \%$ of landscapable area. Landscape horticulturists wishing to assign a name to urban landscapes could base the name on the materials that dominate the landscaped area.

Surprisingly, shrubs did not feature in the name of common landscape types and occurred only once in the name of a minor landscape type. This can be explained by the fact that despite their frequent occurrence, shrub coverage was lower than $30 \%$ (Fig. 3). In contrast, turf featured in the name of several common landscape types. The coverage ratio of warm season grass areas to cool and mixed season grass was 11:1 (Table 3 ). These results sharply differ from those of Hurd et al. (2006), where respondents' self-reported data showed a 2:1 ratio for warm season grass areas to cool and mixed season grass for Las Cruces. The possibility that homeowners in Las Cruces might confuse warm and cool season grass may explain the difference between our results and those of Hurd et al. (2006). We observed that the homeowners had difficulty in identifying the turfgrass species in their landscapes. Warm season grass is most suitable for warm/arid areas such as Las Cruces (Christians, 2004). Therefore, the dominance of warm season grass in Las Cruces residential landscapes indicated that landscape personnel are cognizant of that fact.

Homeowners select plant species mainly based on their aesthetic value (Spinti et al., 2004; St. Hilaire et al., 2008; Yabiku et al., 2008), plant functionality, availability, and cost (Spinti et al., 2004) and not exclusively on their water-use level. This multiplicity of factors increases variation in wateruse level in homeowners' landscape and might explain the variation in water-use level, although the total number and variety of plants did not differ among common landscape types. That very low, low, low-to-moderate, and moderate water-use plants covered $55 \%$ of common landscape types suggests more plants with lower water-use levels can still be accommodated in common landscape types in Las Cruces.

Aesthetic and economic benefits (Chalker-Scott, 2007), labor and maintenance savings (Sovocool et al., 2006), and reduced evapotranspiration from the landscape (Xie et al., 2006) might explain the popularity of mulch in Las Cruces landscapes. Gravel was the dominant mulch type. Gravel size is positively correlated with evaporation (Yuan et al., 2009). So, fine-textured gravel $(<10 \mathrm{~mm})$ should enable greater water savings than the more popular medium-textured gravel $(\geq 10$ and $\leq 40 \mathrm{~mm}$ ). Although gravel-covered surfaces have reduced evaporation rates compared with bare soil (Singer and Martin, 2008), Mueller and Day (2005) observed that gravel increases canopy surface temperatures, air temperatures, and vapor pressure deficits. A practical solution to this dilemma would be the use of landscape materials that provide the benefits of gravel mulch but have less impact on the landscape's microclimate.

A major strength of our method is that we detected differences in frontand backyard landscapes because we divided landscape area into zones. While survey information (Spinti et al., 2004; St. Hilaire et al., 2010) has shown differences in homeowner preferences for front- and backyard landscape types in desert environments, our data provide quantitative evidence that the distribution of landscape types differs in front- and backyard landscapes in the desert environment of Las Cruces. That the mulch common landscape type was the dominant landscape 
type in the frontyard provides quantitative evidence that Las Cruces residents preferred low-maintenance and low-cost landscapes for that area of their landscape.

Earlier, Spinti et al. (2004) reported that $51 \%$ of Las Cruces homeowners preferred "southwestern U.S. desert-type landscape" in the frontyard. While the topography of southern New Mexico causes a mosaic of floodplain, arroyo, Chihuahuan Desert, grassland, savannah, and forest native vegetation types, the characteristic southwestern U.S. desert-type vegetation is the Chihuahuan Desert vegetation (Dick-Peddie, 1975). The typical Chihuahuan Desert site has a rocky surface and the native vegetation consists of xeric shrubs with occasional patches of hardy grasses (Dick-Peddie, 1975). Residents of Las Cruces have cited shade as an important reason for using trees (Spinti et al., 2004). Therefore, it is not surprising that the turf tree landscape and the hard-surface shade-structure landscape types, which provide the shade that Chihuahuan Desert sites lack, were among the most common landscape types in the backyard.

\section{Conclusions}

Ninety-three percent of residential landscape zones could be classified into nine common landscape types. A limitation of our method is that we selected $30 \%$ coverage as the cutoff point for naming the common landscape type. This element of subjectivity was inescapable, but we limited its impact by exploring how different coverage percentages would impact our classification. Although they occurred frequently, a surprising result was that shrubs did not feature prominently in landscape nomenclature because of their low coverage. A mulch-dominant landscape type formed the majority of common landscape types and was the most prevalent type in frontyards. The success of our quantitative method of classification allowed us to identify multiple landscape types and confirm differences between front- and backyard landscape distribution. The practical value of this research is that common landscape types can be linked to landscape budgets that, as St. Hilaire and AlAjlouni (2009) have shown, can be the basis for managing urban landscape water resources in desert environments.

\section{Literature cited}

Al-Kofahi, S.D., D.M. VanLeeuwen, Z.A. Samani, and R. St. Hilaire. 2012a. A water budget calculator created for residential urban landscapes in Albuquerque, New Mexico. J. Irrig. Drain. Eng. 138:525533.

Al-Kofahi, S.D., D.M. VanLeeuwen, C.S Steele, and R. St. Hilaire. 2012b. Mapping land cover in urban residential landscapes using very high spatial resolution aerial photographs. Urban For. Urban Green. 11:291-301.

Chalker-Scott, L. 2007. Impact of mulches on landscape plants and the environment. J. Environ. Hort. 25:239249.

Christians, N. 2004. Fundamentals of turfgrass management. Wiley, Hoboken, NJ.

City of Las Cruces. 2008. City of Las Cruces property and zoning information. 15 Nov. 2008. <http://mapserver.lascruces.org/website/zoneparc/viewer. htm>.

Costello, L. and K.S. Jones. 1999. A guide to estimating irrigation water needs of landscape plantings in California. Univ. California Coop. Ext., California Dept. Water Resources, Sacramento, CA.

Dick-Peddie, W.A. 1975. Vegetation of southern New Mexico, p. 81-84. In: W.R. Seager, R.E. Clemons, and J.F. Callender (eds.). New Mexico Geological Society guidebook. 26th Field Conf. 23 May 2013. <http://nmgs.nmt.edu/ publications/guidebooks/downloads / 26/26_p0081_p0084.pdf>.

Godefroid, S. and N. Koedam. 2007. Urban plant species patterns are highly driven by density and function of built-up areas. Landscape Ecol. 22:1227-1239.

Grimm, N.B., J.M. Grove, S.T.A. Pickett, and C.L. Redman. 2000. Integrated approaches to long term studies of urban ecological systems. Bioscience 50:571584 .

Hunter, S.C. and T.E. Paysen. 1986. Vegetation classification system for California: User's guide. U.S. Dept. Agr., For. Serv., Pacific Southwest For. Range Expt. Sta., Gen. Tech. Rpt. PSW-94. 5 Apr. 2010. <http://www.fs.fed.us/psw/ publications/documents/psw_gtr094/ psw_gtr094.pdf>.

Hurd, B.H., R. St. Hilaire, and J.M. White. 2006. Residential landscape, homeowner attitudes and water-wise choices in New Mexico. HortTechnology 16:241-246.
Kenney, D., R. Klein, and M. Clark. 2004. Use and effectiveness of municipal water restrictions during drought in Colorado. J. Amer. Water Resources Assn. 40:7787.

Klein, R. 1989. Concrete and abstract Voronoi diagrams. Springer-Verlag, Berlin, Germany.

Larsen, L. and S. Harlan. 2006. Desert dreamscapes: Landscape preference and landscape behavior. Landsc. Urban Plan. 78:85-100.

Martin, C.A. 2003. Landscape water use in a desert metropolis. Consortium for the study of rapidly urbanizing regions, research vignette No.1. 9 May 2009. <http://ces.asu.edu/csrur/research\% 20vignette $\% 201 . p d f>$.

Mueller, E.C. and T.A. Day. 2005. The effect of urban ground cover on microclimate, growth and leaf gas exchange of oleander in Phoenix, AZ. Intl. J. Biometeorol. 49:244-255.

Myeong, S., D. Nowak, R. Brock, and P. Hopkins. 2001. Urban cover mapping using digital, high spatial resolution aerial imagery. Urban Ecosyst. 5:243-256.

Ramsey, F.L. and D.W. Schafer. 2002. The statistical sleuth, a course in methods of data analysis. 2nd ed. Duxbury Press, Belmont, CA.

Richards, N.A., J.R. Mallette, R.J. Simpson, and E.A. Macie. 1984. Residential greenspace and vegetation in a mature city: Syracuse, New York. Urban Ecol. 8:99125.

Singer, C.K. and C.A. Martin. 2008. Effect of landscape mulches on desert landscape microclimates. Arboricult. Urban For. 34:230-237.

Sovocool, K.A., M. Morgan, and D. Bennet. 2006. An in-depth investigation of xeriscape as a water conservation measure. J. Amer. Water Works Assn. 98: 82-93.

Spinti, J.E., R. St. Hilaire, and D. VanLeeuwen. 2004. Balancing landscape preferences and water conservation in a desert community. Hort Technology $14: 72-77$.

St. Hilaire, R. and M.G. Al-Ajlouni. 2009. Linking landscape types to water use in residential landscapes. HortScience 44:1162 (abstr.).

St. Hilaire, R., M.A. Arnold, D.A. Devitt, B.H. Hurd, B.J. Lesikar, V.I. Lohr, C.A. Martin, G.V. McDonald, R.L. Morris, D.R. Pittenger, D.A. Shaw, D.C. Wilkerson, and D.F. Zoldoske. 2008. Efficient water use in residential urban landscapes. HortScience 43:2081-2092. 
St. Hilaire, R., D. VanLeeuwen, and P. Torres. 2010. Landscape preferences and water conservation choices of residents in a high desert environment. HortTechnology 20:308-314.

Sun, X. and Z. Yang. 2008. Generalized McNemar's test for homogeneity of the marginal distributions. 9 July 2011. <http://www2.sas.com/proceedings / forum2008/382-2008.pdf $>$.

Xie, Z., Y. Wang, W. Jiang, and X. Wei. 2006. Evaporation and evapotranspiration in a watermelon field mulched with gravel of different sizes in northwest China. Agr. Water Mgt. 81: 173-184.
Yabiku, S.T., D.G. Casagrande, and E. Farley-Metzger. 2008. Preferences for landscape choice in a southwestern desert city. Environ. Behav. 40:382400.

Yuan, C., T. Lei, L. Mao, H. Liu, and Y. Wu. 2009. Soil surface evaporation processes under mulches of different sized gravel. Catena 78:117-121. 